\title{
Affective Scaffolding to Mediate the Use of Emergent Technology
}

\author{
Maria Antonietta Impedovo \\ ADEF, Aix-Marseille University \\ Афективно скеле за посредничество при използването на \\ нововъзникващи технологии \\ Мария Антониета Импедово \\ ADEF, Университет Екс-Марсилия
}

\begin{abstract}
Author Note
Maria Antonietta Impedovo https://orcid.org/0000-0003-2172-7105

The author has no known conflict of interest to disclose.

Correspondence concerning this article should be addressed to Maria Antonietta Impedovo, Aix-Marseille Université - Campus Etoile, BATIMENT RTP,52 Av. Escadrille Normandie Niémen, Marseille, 13013. Email: maria-antonietta.IMPEDOVO@univ-amu.fr
\end{abstract}

\section{Бележки за автора}

Мария Антониета Импедово (D) https://orcid.org/0000-0003-2172-7105

Авторът няма известен конфликт на интереси за разкриване.

Кореспонденцията относно тази статия следва да бъде адресирана до Мария Антониета Импедово, Екс-Марсилия Université - Campus Etoile, BATIMENT RTP, 52 Av. Escadrille Normandie Niémen, Марсилия, 13013. Имейл: mariaantonietta.IMPEDOVO@univ-amu.fr 


\begin{abstract}
Technology is reshaping the micro-ecologies of developing, becoming a part of it. It impacts and enables reconfiguration of social interaction in everyday situations. The study aims to bring a macro and micro discussion about close interconnection with complex technology and how these interactions have reciprocal implications between materiality and subjectivity. The broad research question is: How do we deal and interact with daily increasingly complex technology? A theoretical perspective is outlined about the subject and object relationship, focusing on new technology in the baby day living. One key point stressed in this paper is the affective scaffolding that could be a key point for social mediation with technology. To support the reflection, some illustrative examples are proposed from a naturalistic observation. In particular, the study focus on one 1-years old baby interacting with a smartphone and a robot toy. A final discussion is proposed to discuss the material and subjective dialectic interactions.

Keywords: materiality, infant studies, interaction with technology, affective scaffolding

\section{Резюме}

Технологията преоформя микроекологията на развитието, ставайки част от нея. Тя въздейства и позволява преконфигуриране на социалните взаимодействия в ежедневни ситуации. Изследването има за цел да доведе до макро и микро дискусия за тясната взаимовръзка със сложните технологии и как тези взаимодействия имат реципрочни последици между материалността и субективността. Обширният изследователски въпрос е: Как се справяме и взаимодействаме с ежедневните все по-сложни технологии? Очертана е теоретична перспектива за връзката субект и обект, като се фокусира върху новите технологии в живота на едно бебе. Един ключов момент, подчертан в тази сттия, е афективното скеле, което може да бъде ключов момент за социалното посредничество с технологиите. В подкрепа на разсъжденията са предложени някои илюстративни примери от конкретно естествено наблюдение. По-специално, проучването се фокусира върху едногодишно бебе, което взаимодейства със смартфон и играчка робот.

Ключови думи: същественност, детски изследвания, взаимодействие с технологиите, афективно скеле 


\section{Affective Scaffolding to Mediate the Use of Emergent Technology}

The study focuses on experiences with increasingly complex technical objects, with some illustrative examples from infants' interactions with everyday technology.

In an “acceleration of everything' (Gleick, 2000; Global Internet Use Report 2019), everyday technology acts as an active and transformative force into reality (Pea \& Cole, 2019). Virtual /Augmented /Mixed Reality, Sensory Augmentation Technologies, Artificial Intelligence, Robotics as emergent technology are spreading in our classroom, informal learning settings and home.

Considering these broad reflections and the call for an urgent redefinition of the same notion of 'the human' (Ferrando, 2019; Hayles, 2008), it is interesting to focus on human development's very early ecological niche. Indeed, infants are immersed from birth in a material culture whose objects are part of ongoing everyday activities (Impedovo \& Tebet, 2019). However, how they interact with it is still under exploration (Gillen \& Kucirkova, 2018). Understanding how emerging technology could create new cultural conditions for babies and children's development becomes increasingly important. This article aims to bring a macro and micro discussion about how we are closely interconnected with complex technology and how these interactions have reciprocal implications between materiality and subjectivity. The broad research question is: How do we deal and interact with daily increasingly complex technology?

In the following, a theoretical perspective is outlined about the subject and object relationship, focusing on new technology in the baby day living. To support the reflection, some illustrative pictures of infants are proposed from a naturalistic observation.

The study goes into the direction to question our relationship with the technological world around us, going to the roots of our subject and object dialectic - especially, at this time of digital, social, technological, and economic transformation driven by increasing diversity and inequality in the world - the number of poor increased to 734.5 million people. The argumentation is inspired by debates in science and technology studies (Sørensen, 2009; Suchman, 2007).

\section{Subject and Object Relationship}

In the philosophy of technology, the object has a central role in the slow and cumulative technological development of humanity at work (DiGironimo, 2011). Some perspectives are here briefly discussed related to a central role of the artefact (Impedovo et al., 2015; Wartofsky, 1973), here considered as everything on that human have acted a transformation. 
The "revolution" introduced by Vygotsky (1978) was to break the behaviourism chain, which considered the direct connection between subject and object. Indeed, the artefact was introduced as a mediating element, even a psychological tool, more oriented to expand the scope of psychological processes and make possible cognitive development. Artefacts condense the signs of the historical and cultural context in which they are created. They are continuously recreated through their use, making the culture a system of accumulated artefacts of a community (Cole 1996). Artefacts are included in a dynamism of expanding cycles (Engestrom 1987) where the artefact can evolve into a complex tool for another activity, different from the original one. The appropriation process includes the mutual influence and simultaneous transformation between the object and the users (Overdijk \& van Diggelen, 2008). This process of mutual shaping between the tool and the subject recalls the so-called instrumental approach (Beguin \& Rabardel, 2000): the instrument is constructed through an instrumental genesis, a process of appropriation during which a bilateral relationship between the tool and the subject is established. In fact, under distributed cognition theory, while carrying out an activity, people project structures of intentionality onto the context, which thus becomes an integral part of human thought and action (Hollan et al., 2000).

A second critical perspective that gives a unique role to the object is the Actor-network theory (ANT), which describes the 'how' of phenomena. Although Latour (1996) does not fully accept the notion of object, he talks about objects as concrete heterogeneous material-semiotic entities. Any object can be analysed as an actor so long as it plays a significant role in constructing a network. Things must be constantly built and performed in a network and connected with other actors (Latour, 2003).

In a different perspective, Knorr Cetina (2001) discusses two processes: individualisation and objectualisation. Individualisation is an orientation towards other people as a source of self and alienation from others based on the collapse of community and traditions in modern capitalist society. The objectualisation is an increased orientation towards objects as sources of the self, relational intimacy, and social integration. To overcome the presented dualism, Knorr Cetina suggests the notion of post-social relationships: new kinds of bonds such as those constructed between humans and objects.

These three complementary orientations show the complex relationship between the human and the artefacts. Although the three approaches have different philosophical, disciplinary and methodological backgrounds, they all contribute to show theoretical tensions and reflexive paths between human subjectivity and materiality: 
"it is not only the subjects that do something with the things; the Things also do something with the subjects. To make it clear that, on the one hand - in line with the objectification concept — human subjectivity and agency are materialised in the object, while, on the other hand, the materiality of the object can release an independent power and efficacy, propose to conceptualise the created objects as materialised action" (Schraube, 2009, p. 300).

Generally, the material culture did not receive the same attention and was neglected by mainstream traditions (Moro, 2015; Sørensen, 2009). Materiality is here understood as a connection to other entities, both physical and social. At the same time, there is more attention to how the semiotic landscape is connected to the real world of social praxis (Daniels, 2010): it does not reside exclusively within the discursive processes but also into both semiotic and material context in which the sensemaking is embedded (Salvatore \& Venuleo, 2013).

In the future, we can question if the object became the relevant side in the relationship $(S<O)$, alternating a relation of the superiority of the subject $(S>O)$ or a symmetrical value between them $(\mathrm{S}=\mathrm{O})$. In this study, we consider that the main future challenge is to address our ability to respond to technology and keep open our possibility of creative acting into reality. The following section explores how technology and technical objects are pervasive in the daily environment, shaping the possible configurations of actions.

\section{When the Natives will be the Robots}

Technology is reshaping the micro-ecologies of developing, becoming a part of it. It impacts and enables reconfiguration of social interaction in everyday situations. At the same time, emergent technology is oriented to develop practical applications and to model human cognition.

For example, social robotics is a fast-growing research field geared toward the design and study of 'autonomous' robots that are expected to engage in social interaction with humans in a different field (Alač, Movellan \& Tanaka, 2011). At the same time, social robots are conceived as testing platforms for theoretical models of human cognitive abilities, for example, the interdependencies between the mind and the body. Considering that social robots have a physical body, new possible social and material reconfiguration interactions emerge into the robots' interactions, as shown by the work of Hasse (2020). In Figure 1, two illustrative pictures: in the first, a 1-year-old baby is discovering a robot-toy, which makes music, move on the six legs like dancing. The baby is attracted by the toy, following it with the body and the gaze. In the second picture, Figure $1 \mathrm{~b}$, a security robot machine moves around people in the 
Tokyo airport to check the respect of Covid-19 sanitary obligations. The moving camera gives the impression to search the human contacts and goes quite close to the people, like in the pictures, apparently addressed its speech to a woman interacting whit her smartphone.

\section{Figure 1a; b}

1a) a baby with a toy robot; 1b) a security robot - personal archive.
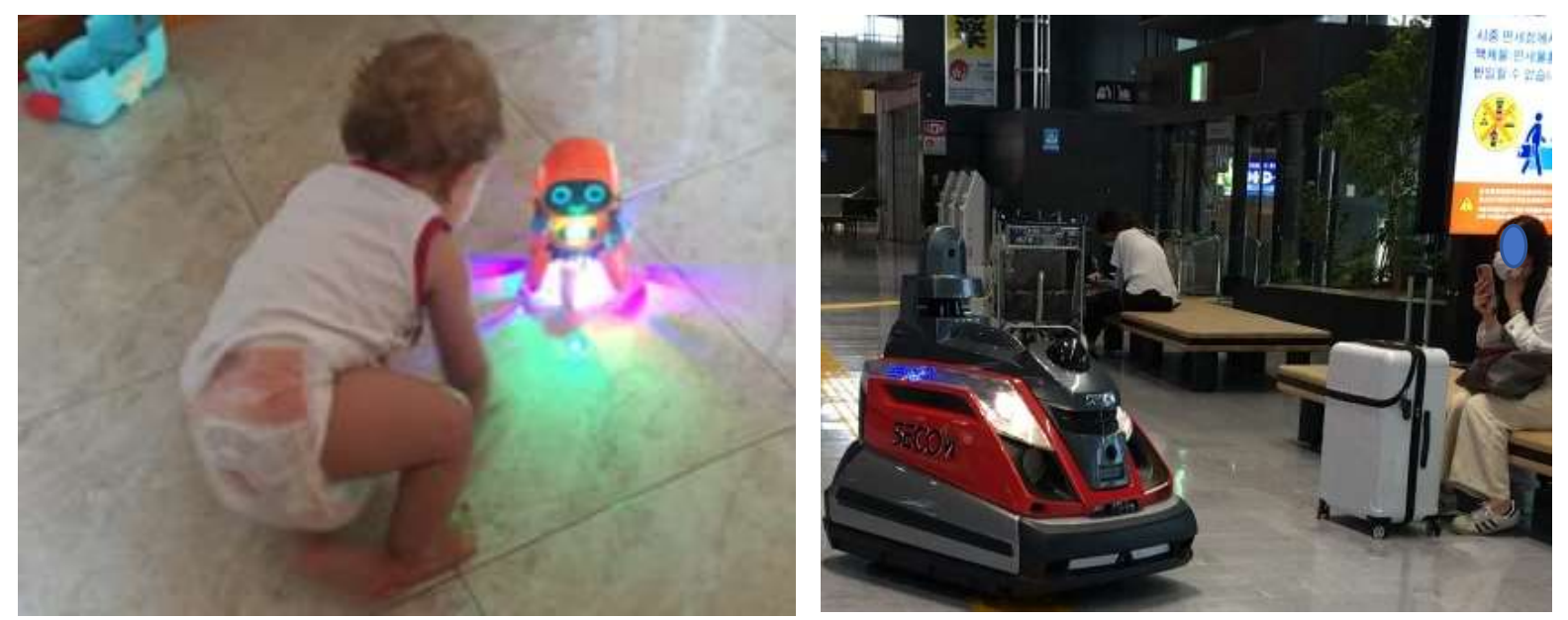

Understanding the social nature of material objects and the situated character of human bodies involved in interaction cannot be complete until we are willing to carefully observe the richness of everyday activities in the environments in which the bodies of social actors (included new and emergent technology) are designed and enacted.

One key point stressed in this paper is the affective scaffolding that could be a key point for social mediation with technology. The following section focuses on the affective dimension as a mediator of complex technology use and appropriation.

\section{Inside the Technological Niche: Affective Scaffolding}

The notion of Affective Scaffolding is here adopted as a possible mediator in the appropriation and use of complex technical objects and emergent technology. As defined by Candiotto and Dreon (2021), "affective scaffolding is a unique hermeneutical tool that plays a fundamental role in drawing attention to the continuous and recursive interactions with the environment shaping affectivity" (pag. 3).

The reflection started with Griffiths and Scarantino (2008), in the paper "Emotions in the wild", understanding emotions as both social and intersubjective phenomena. It is proposed as an example of "situated affectivity": the environment influences and is influenced by the unfolding of emotions, constantly reframing the relationships and offering action possibilities 
in the form of emotions. The social embeddedness of emotions is both synchronous (supporting an emotional episode) and diachronic (supporting the development of a repertoire of emotional abilities). Affective scaffolding is those resources that contribute to affective regulation if integrated into structured and repeated interaction practices.

Krueger (2018) proposes three distinctions:

a) the embodied affective scaffoldings; in which the affective experience is regulated by a range of physical processes distributed throughout our bodies, like digestion;

b) social, affective scaffoldings, in which socially distributed feedback loops regulate the affective dynamics of individuals and groups like family dinner;

and c) material affective scaffoldings, in which affectivity is regulated by the material culture that is made up of particular objects and environments like a wedding dress.

The affective habit incorporation is detected primarily in the body (Colombetti, 2016). Recently, Candiotto and Dreon (2021) stressed the habits in the affective scaffolding to shape the interactions.

The affective scaffolding is here adopted as a valuable concept to interpret the relationship with technology. In a baby with a grandparent's arm, like in Figure 2a, the arm became the adequate technology to sustain the baby and keep it safe, secure and in an excellent emotional state in the car. The body became a site of every technical procedure's intersection, interfaces, and interactions (Nancy, 2000). In this micro situation, the arms play a replacement role for the stroller on the seat, which is mandatory for babies. To calm the baby in a moment of crying crisis, the grandmother played the role of the stroller: her arms contain, protect and, more, immediately calm the baby.

In Figure 2b, we can see a 1-year baby on the slipway with the 2-years old sister and grandmother on the playground. In this case, the baby is too small to slide like his sister. The grandmother, on her initiative, takes the child and makes him slide into the last part of the slide, simulating the activity just carried out by his sister, who observes the scene. Grandma's arms are the material and corporal scaffolding technology that allows the child to experience the slide. In this case, her arms assist the otherwise impossible action in an effective and affective way.

A creative parallel with the scaffolding proposed by the grandmothers in Figures 1a and b could be proposed like in the imaginary reality of cartoons in robot superheroes. Figures $2 \mathrm{c}$ and d show two focuses from the Mazinger $\mathrm{Z}$ cartoon: the human-hero in the robot's control unit, behind the wheel and ready for combat action. The heroes-robots plays the same role as 
the physical scaffolding of the grandmother. Indeed, the technology could act as a safe, secure artefact to mediate the interaction with the environment, like the car itself or an aircraft: the body is protected by the seat belt while the machine is exposed to wind, rain, speed. Suppose the affettive reciprocal relationship is evident in the baby-grandmother interactions. In that case, we can question the affective relationship between the human hero and the robot-hero: in our knowledge, in the cartoon, not the hero or the robot never questions and meta-analysis their relationship and where the boundaries between them are situated.

\section{Figure 2a; b; c; d}

a - One year baby with grandparents in a car - personal archive;

$b$ - One year baby on the slipway with the 2-years old sister and grandmother on the playground-personal archive;

$b$ - The cartoon technology in Mazinger $Z^{1}$
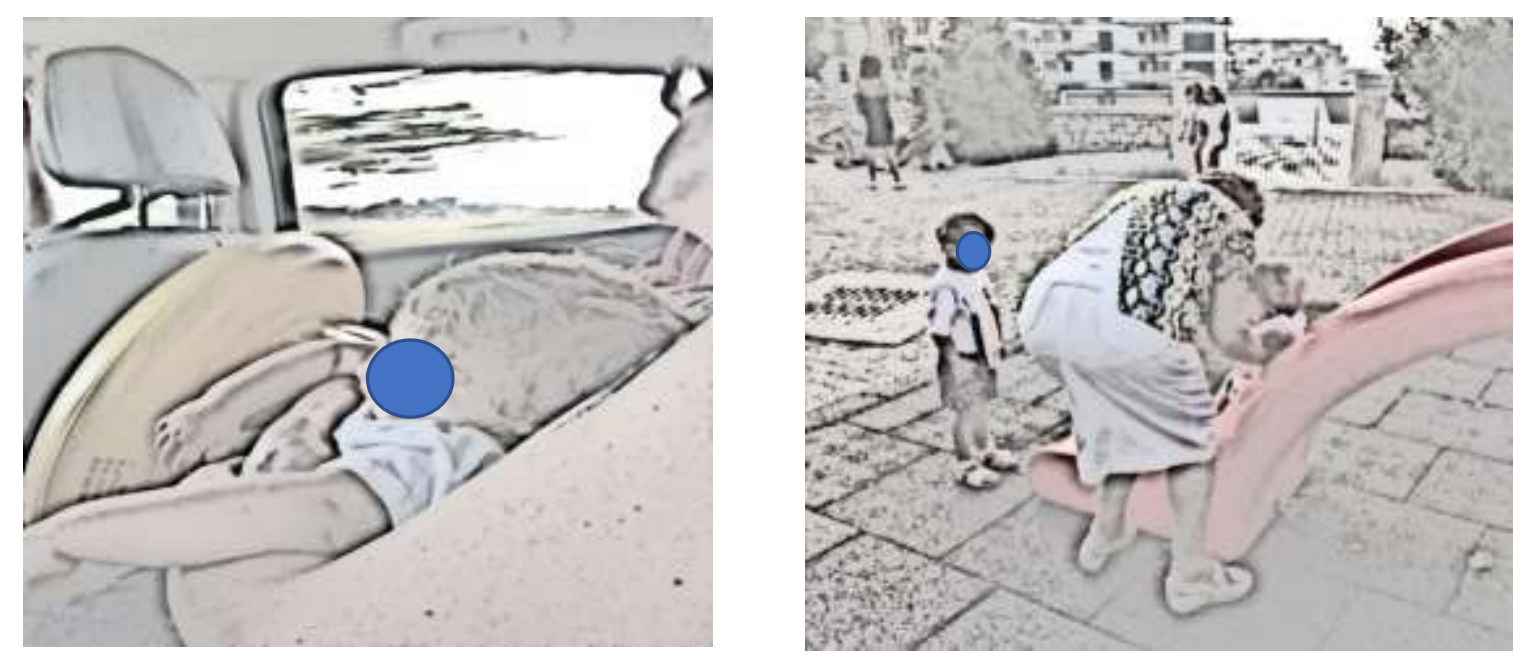

\footnotetext{
${ }^{1}$ Copyright: https://www.hollywoodreporter.com/news/general-news/mazinger-z-infinity-sets-world-premiereat-rome-film-fest-1039669/ ; https://www.youtube.com/watch?v=mf54FujwBkw About Mazinga Z: https://en.wikipedia.org/wiki/Mazinger_Z:_Infinity
} 

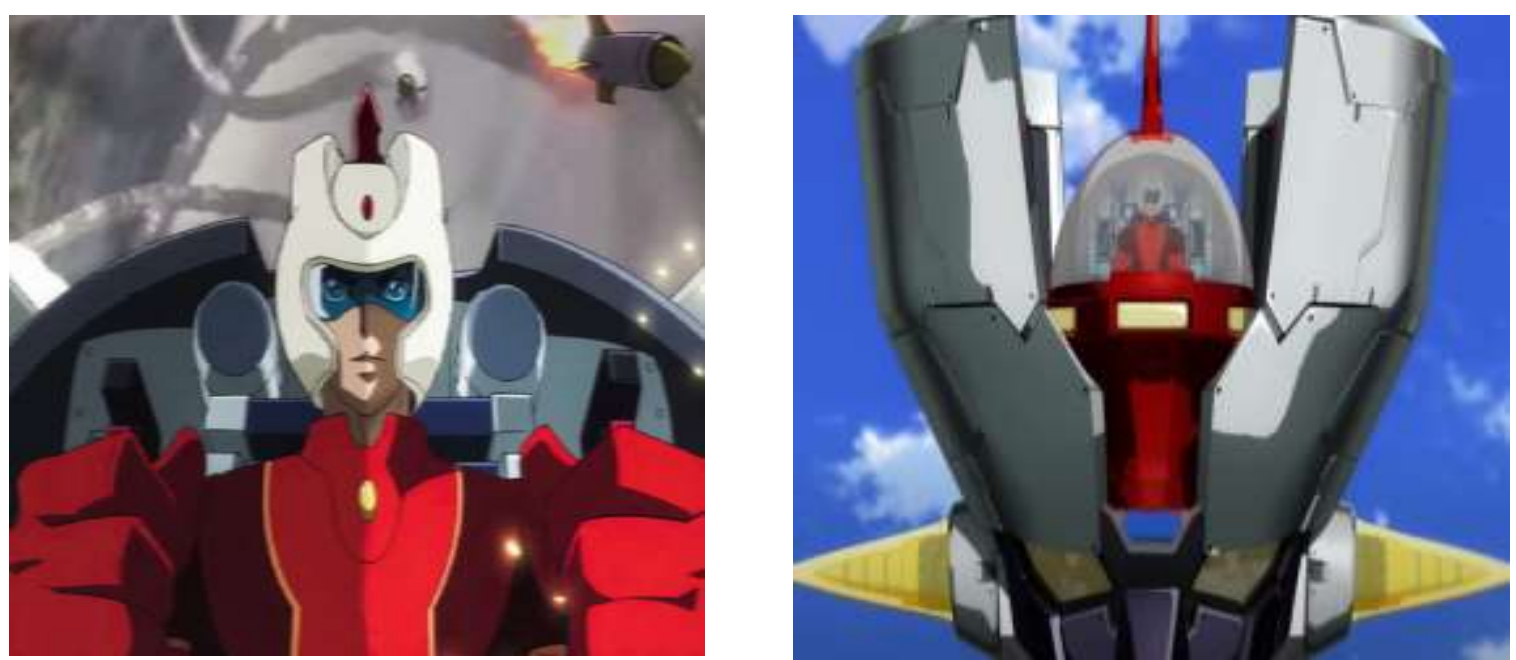

In the following section, more examples are proposed to show the affective scaffolding regulation with technology in the baby's niche.

\section{Affective Scaffolding Regulation}

Daily, we experience the baby intention to touch and desire the caregivers' phone (Knitter \& Zemp, 2020). In the following, we report two micro -observations: in the first episode, the 1years old baby and his grandmother (GM) interact with a smartphone; in the second episode, the 1-years old baby interact with a robot-toy.

In Figure 3, we observe a video of about twelve seconds. The baby performs the gesture of touching the smartphone screen in a kind of imitation of adult touching. The baby acts a mimetic pathos (Lawtoo, 2019; 2020), considering the humans are open to a plurality of mimetic effects that include but are not limited to desire. The mechanical interaction between the baby and the smartphone is quickly regulated to the grandmother. She is watching the baby actions, but suddenly she interrupts the baby free explorative actions. Her reaction is due to the concern by the baby's well-being and of her smartphone's well-being (considering it is new and she uses it carefully); more, it is solicited to the baby's mother apprehension near to them, which is driving so cannot intervein directly but ask to check the baby actions.

\section{Figure 3}

Baby with a smartphone

Time: 00:00

GM: "Ohohoh" (irritated)
00:03

00:04

GM: "Now I give him GM: "So I take it off" another object in his hand like this" 


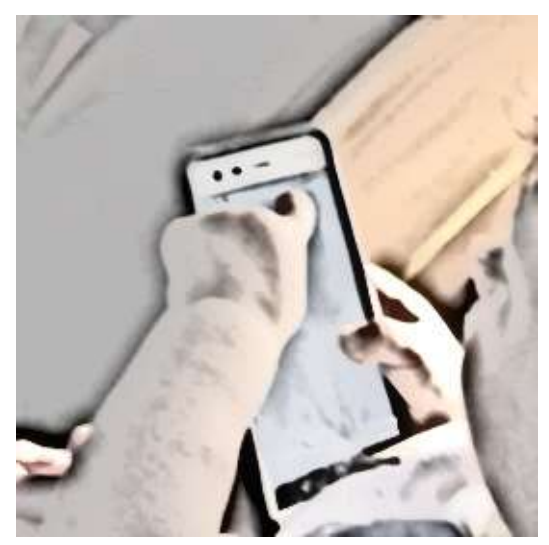

00:09

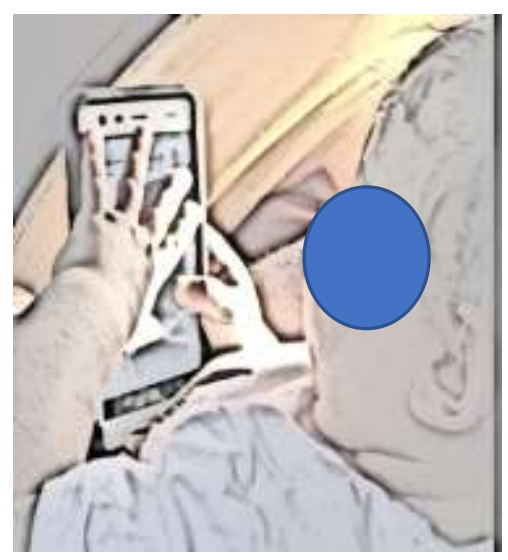

$00: 11$

GM: "Oh oh no"

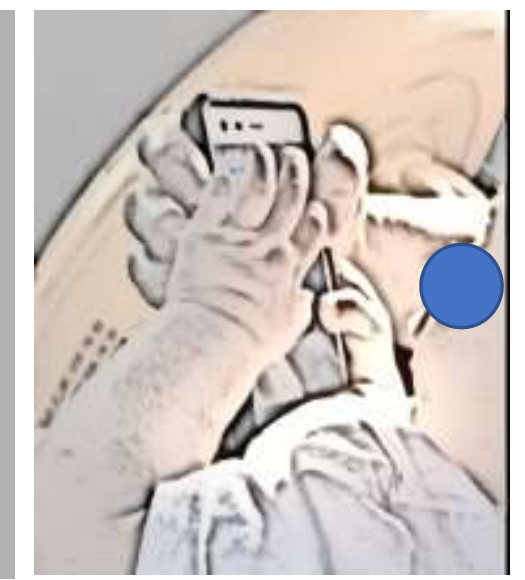

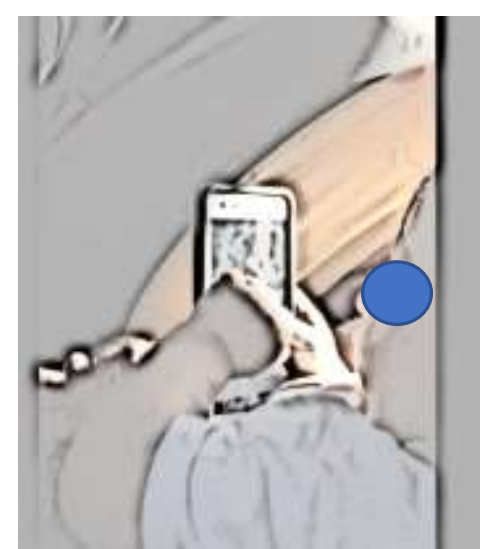

$00: 12$

GM: "to grandma, give it to me!"

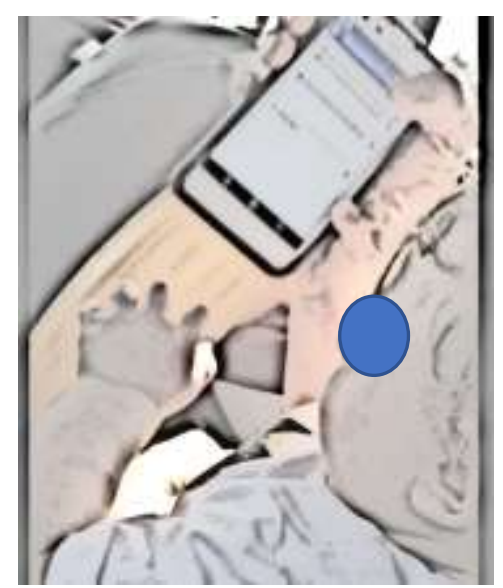

In Figure 4, it is explored a video of twelve seconds. A 1-year-old baby play with the toy robot - see before in Figure 1. The mother turns on the toy, who observes the infant with the new toy, given as a gift the day before. The infant is immersed in the interaction, even performing a mimic dance, moving the arms and legs. The mother watches, amused and intervenes, asking what she is seeing. As a reaction to the verbal question, the baby interrupts the imitation and requests the affective relationship of the mother, extending your arm in her direction.

\section{Figure 4}

1- year old baby with the toy-robot (personal archive)

00:03

Object moves

He watches attentively

The toy is approaching him
00:04

The baby moves leg and arms as

dancing with the toy-robot 


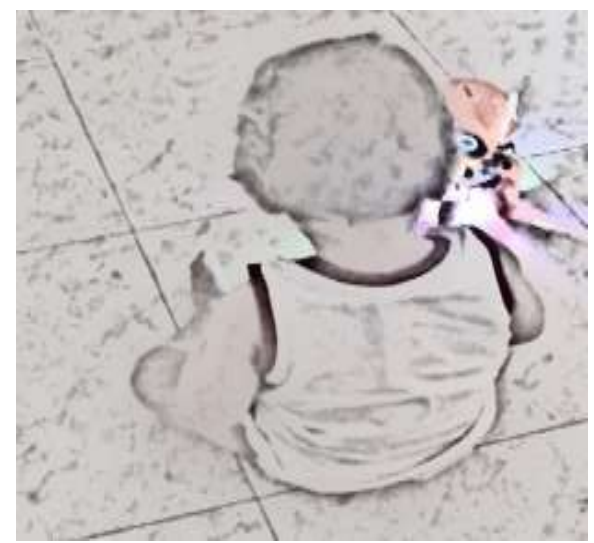

00:08

The mother approaches

"What are you doing?

What is it?"

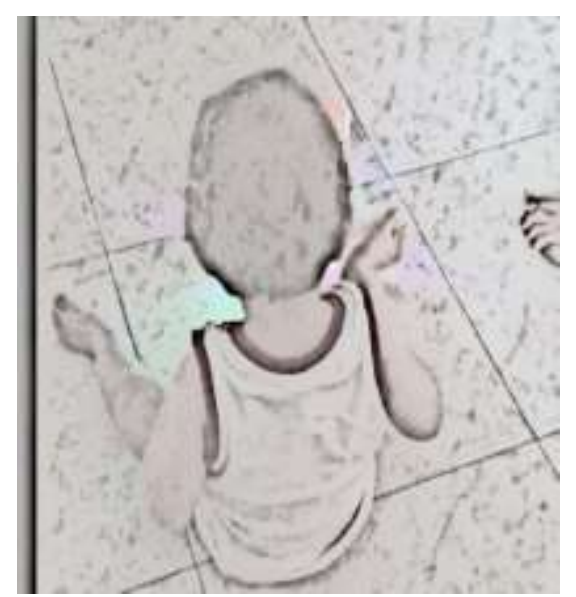

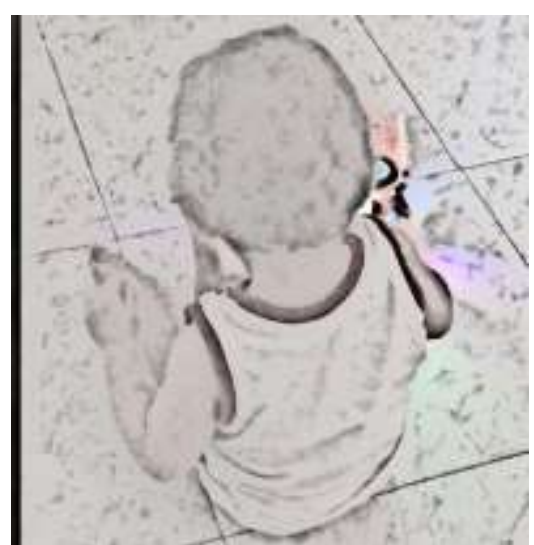

$00: 10$

Baby turns away from the toy to reach

the mother, requiring her attention.

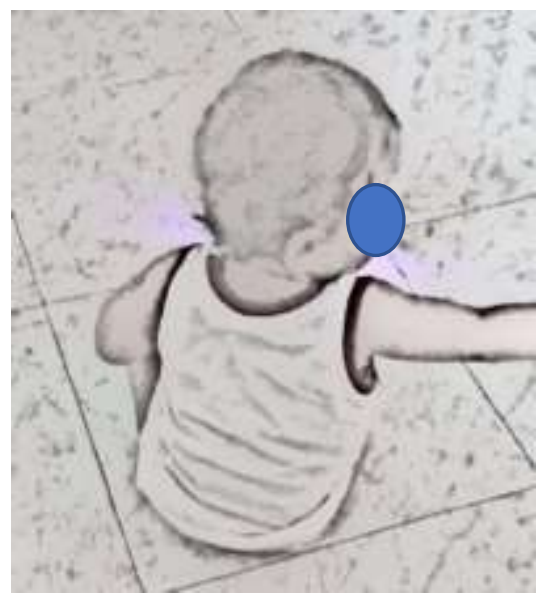

In the first episode, the grandmother interventions regulate the baby's interactions with technology (external affettive regulation); in the second episode, the baby's interaction with the toy robot is regulated by himself, searching the mother (internal affettive regulation).

The interactive process with the smartphone and the toy becomes a baby's learning moment on discovering the technological environment around. This learning is material and social at the same time, with a solid affective mediation: "We learn with material and social relations. Learning is a process of cultural mediation. Building a link between historical process from one hand, and the individual mental process, on the other" (Wertsch, 2007, p. 178).

\section{Discussion and Conclusion}

This study follows preview publications (Impedovo \& Tebet, 2019; Tebet, Impedovo \& Pontes, 2021), which focused on boundaries and how to improve the quality of development of infants in the daily technical environment around them. 
This paper stresses how "objects emerge in the relations rather than having proprieties sui generis" (Suchman, 2005, p. 381). With the help of some illustrative examples, we see smartphones, toy robots, or other complex technical objects as part of babies' material and social-ecological niche. The inseparability of the individual-environment couple is stressed by the French philosopher Simondon's (1989). Individual development is merged with the environment, like the relationship between the clay with the mould. The brick-making meets two heterogeneous domains (the clay and the mould), always paired. The development of babies' niche, highly technological, enacts the distributed cognition in new rhizomatic possibilities (Hayles, 2008) and human-tech hybridity (Duus et al., 2018).

Human ways of living in the Anthropocene, the interactions with drones, big data, artificial intelligence, and robots open new ethical issues and raise new questions related and challenges, like genetic privacy, technological addiction, environmental sustainability, power and equity. Posthumanism perspectives allow seeing the relationship between humans and technology in inter-connected ways exploring cognition, perception, and awareness codevelopmental implications with technology (Belhassein et al., 2019). The digital revolution developments are interpreted as externalisation - understood as an extension" of our body capacities through technology (Leroi-Gourhan,1993). Simultaneously, there is a complementary reflection based on tracking the internalisation or incorporation of technology.

Overcome a duality as human and non-human actors; new readings are necessary for thinking in more sophisticated ways our increasing interactions with complex and emergent technologies. A deep understanding of our relationship with technology also means shaping the potentiality of individual and collective agentic interactions with the environment. A transformative agency is pivotal in keeping open a creative process of interactions, especially in a possible future society that imposes one-way products, solutions and processes, not always including minority perspectives.

In conclusion, exploring the relationship between humans and technology means adopting the rehabilitation of the materiality dimension in which we live as a connection to other physical and social entities. Understanding how we live with things, and in turn, how things come to live with us calls for methodologies in non-dual reality. This implies an interdisciplinary perspective - also philosophical, critical and cultural posthumanism approaches - to help make sense of emerging transformative interaction with technology. Finally, these reflection joins a collective dream of human flourishing and technology co- 
evolution into a healthy relationship. The shift is to producing context to be experienced, in a conscious approach to exploring individual and the collective possibilities of action.

Considering the massive introduction of technology in daily life, in future research, we would like to question how a reduced or massive exposure to complex technologies could influence, facilitate or reduce the possibilities and opportunity to interact fully with the environment for creative and adaptive development: How we can participate to the co-evolution of the humans' capacities and intelligent technology? The investigation became worthy of exploring to understand, reduce and bring awareness about digital structural inequality (UNESCO, 2021), already made evident by COVID-19 impacts.

\section{References}

Alač, M., Movellan, J., \& Tanaka, F. (2011). When a robot is social: Spatial arrangements and multimodal semiotic engagement in the practice of social robotics. Social Studies of Science, 41(6), 893-926.

Beguin, P., \& Rabardel, P. (2000). Designing for instrument-mediated activity. Scandinavian Journal of Information Systems, 12, 173-190. https://aisel.aisnet.org/sjis/vol12/iss1/1/

Belhassein, K., Cochet, H., Clodic, A., Guidetti, M., \& Alami, R. (2019). From Children to Robots: How the parallel with developmental psychology can improve human-robot joint activities. Joint Action Meeting.

Candiotto, L., \& Dreon, R. (2021). Affective Scaffoldings as Habits: A Pragmatist Approach. Frontiers in Psychology, 12, 945. https://doi.org/10.3389/fpsyg.2021.629046

Daniels, H. (2012). Institutional culture, social interaction and learning. Learning, Culture and Social Interaction, 1(1), 2-11.

Di Gironimo, N. (2011). What is technology? Investigating student conceptions about the nature of technology. International Journal of Science Education, 33(10), 1337-1352.

Duus, R., Cooray, M., \& Page, N. C. (2018). Exploring human-tech hybridity at the intersection of extended cognition and distributed agency: a focus on self-tracking devices. Frontiers in psychology, 9.

Ferrando, F. (2013). Posthumanism, transhumanism, antihumanism, metahumanism, and new materialisms. Existenz, 8(2), 26-32.

Gillen, J., \& Kucirkova, N. (2018). Percolating spaces: Creative ways of using digital technologies to connect young children's school and home lives. British Journal of Educational Technology, 49(5), 834-846. https://doi.org/10.1111/bjet.12666

Global Internet Use Report (2019) shorturl.at/oJKSV 
Knorr Cetina, K. (2001). Objectual practice. In K. Cetina, E.von Savigny, \& T.R.Schatzki (Eds.), The practice turns into contemporary theory. Routledge.

Hayles, N. K. (2008). How we became posthuman: virtual bodies in cybernetics, literature, and informatics. University of Chicago Press.

Hasse, C. (2020). Posthumanist learning: what robots and cyborgs teach us about being ultra-social. Routledge.

Hollan, J., Hutchins, E. Kirsh, D. (2000). Distributed cognition: toward a new foundation for Human-computer Interaction Research, ACM Transactions on Computer-Human Interaction, 7(2), 174-196.

Impedovo, M. A., Andreucci, C., Ginestié, J. (2015). Mediation of artefacts, tools and technical objects: an international and french perspective. International Journal of Technology and Design Education, 27(1), 19-30. https://doi.org/10.1007/s10798-0159335-y

Impedovo, M.A. \& Guarnieri de Campos Tebet, G. (2019). Baby wandering inside day-care: retracing directionality through cartography. Early Child Development and Care, 112. https://doi.org/10.1080/03004430.2019.1680548

Knitter, B., \& Zemp, M. (2020). Digital family life: A systematic review of the impact of parental smartphone use on parent-child interactions. Digital Psychology, 1(1), 29-43.

Latour, B. (1996). Petite réflexion sur le culte moderne des dieux faitiches. Synthélabo.

Latour, B. (2003). Is remodernization occurring - and if so, how to prove it? A commentary on Ulrich Beck. Theory Culture and Society, 20(1), 35- 48.

Lawtoo, N. (2019). The philosophy of imitation. Focus, EU Research.

Lawtoo, N. (2020). Homo mimeticus: sameness and difference replayed. The Leuven Philosophy Newsletter 27, 9- 21.

Leroi-Gourhan, A. (1993). Gesture and speech. MIT Press.

Nancy, J. L. (2000). Being singular plural. Stanford University Press.

Overdijk, M., \& van Diggelen, W. (2008). Appropriation of a shared workspace: organising principles and their application. International Journal of Computer-Supported Collaborative Learning, 3, 165-192. https://doi.org/10.1007/s11412-008-9038-4

Pea, R., \& Cole, M. (2019). The living hand of the past: the role of technology in development. Human Development, 62(1-2), 14- 39. https://doi.org/10.1159/000496073 
Salvatore, S., \& Venuleo, C. (2013). Field and dynamic nature of sensemaking. Theoretical and methodological implications. Papers on Social Representations, 22(2), 21-1. https://psr.iscte-iul.pt/index.php/PSR/article/view/310

Schraube, E. (2009). Technology as materialised action and its ambivalences. Theory \& Psychology, 19(2), 296-312. https://doi.org/10.1177/0959354309103543

Simondon, G. (1989). Du mode d'existence des objets techniques. Aubier.

Sørensen, E. (2009). The materiality of learning: technology and knowledge in educational practice. Cambridge University Press.

Suchman, L. (2005). Affiliative objects. Organisation, 12(3), 379-399.

Suchman, L. (2007). Human-machine reconfigurations: plans and situated actions. Cambridge University Press

Tebet, G. G., Impedovo, M. A., \& Pontes, L. C. B. (2021). Babies and borders: between individuation and materiality of the infant life. Human Arenas, 1-17. https://doi.org/10.1007/s42087-021-00243-w

UNESCO (2021). It matters how we open knowledge: building structural equity.

Vygotsky, L. (1978). Interaction between learning and development. Readings on the development of children, 23(3), 34-41.

Wartofsky, M. W. (1973). Perception, representation, and the forms of action: towards a historical epistemology. In M. Wartofsky (Ed.), Models: representation and the scientific understanding reidel. Dordrecht.

Wertsch, J. (2007). National narratives and the conservative nature of collective memory. Neohelicon, 34(2), 23-33. 